\title{
Association between endometriosis and heavy metals in a group of Sri Lankan women of reproductive age
}

by

Wedikara Arachchige Nalinda Yasanga Silva

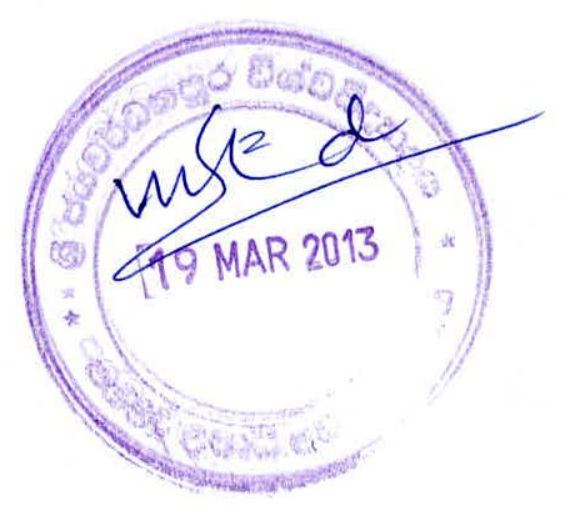

Ph.D. 


\section{Association between endometriosis and heavy metals in a group of Sri Lankan women of reproductive age}

by

Wedikara Arachchige Nalinda Yasanga Silva

Thesis submitted to the University of Sri Jayewardenepura for the award of the Degree of Doctor of Philosophy in Physiology on "Association between endometriosis and heavy metals in a group of Sri Lankan women of reproductive age", on $12^{\text {th }}$ December 2012. 
I certify that the candidate has incorporated all corrections, amendments and additions recommended by the examiners.

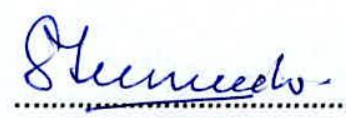

Professor Sharaine Fernando

Professor in Physiology

Department of Physiology

University of Sri Jayewardenepura

Date $12.03 \cdot 13$ 
The work described in this thesis was carried out by me under the supervision of Prof Sharaine Fernando of University of Sri Jayewardenepura, Prof. Hemantha Senanayake and Prof. Kamani Tennekoon of University of Colombo, Dr. Roshini Peiris-John of University of Auckland, New Zealand and Prof. Rajitha Wickramasinghe of University of Kelaniya and a report on this has not been submitted in whole or in part to any University or any other institution for another Degree / Diploma.
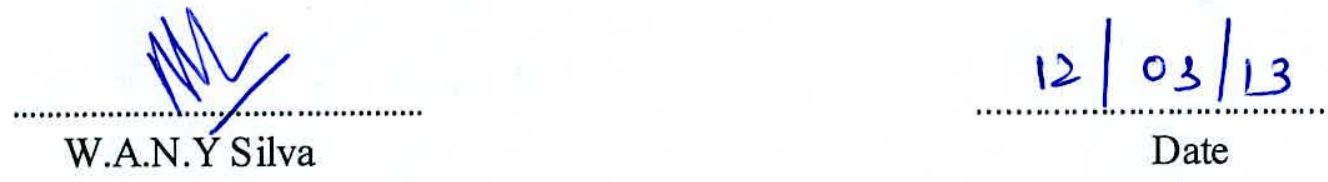
We certify that the above statement made by the candidate is true and that this thesis is suitable for submission to the University for the purpose of evaluation.

\author{
fyemand \\ Professor Sharaine Fernando \\ Professor in Physiology \\ Department of Physiology \\ University of Sri Jayewardenepura
}

Date $12 \cdot 03 \cdot 13$



Professor Hemantha Senanayake

Head

Department of Obstetrics and Gynaecology

Faculty of Medicine

University of Colombo

Date

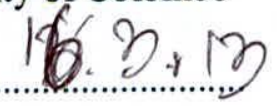

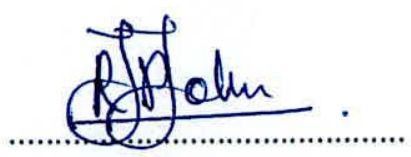

Dr. Roshini Peiris-John

Research Fellow

Section of Epidemiology and

Biostatistics

Faculty of Medical and

Health Sciences

University of Auckland

New Zealand

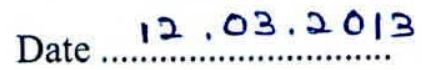

Ict? cuncele.

Professor Kamani Tennekoon

Professor of Molecular Life Sciences

Institute of Biochemistry, Molecular Biology

and Biotechnology

University of Colombo

Date $12,03 \cdot 2013$

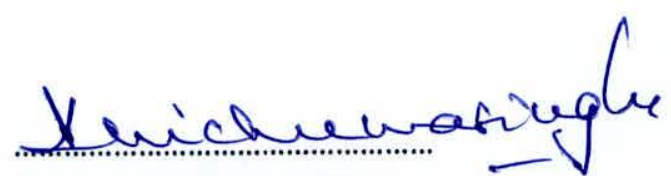

Professor Rajitha Wickramasinghe Professor of Public Health

Faculty of Medicine

University of Kelaniya

Date $1.1+3.1 .2013$ 


\section{TABLE OF CONTENTS}

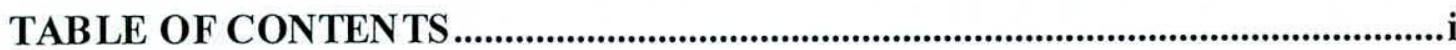

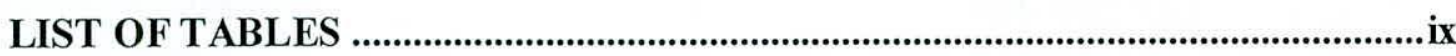

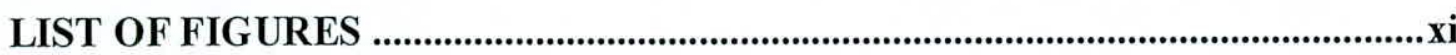

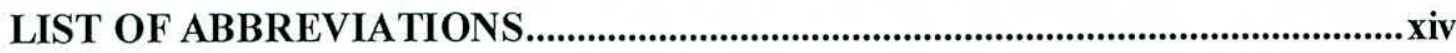

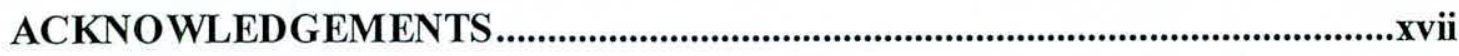

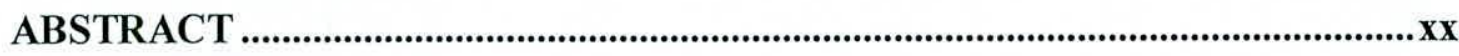

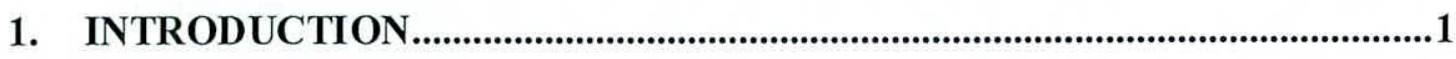

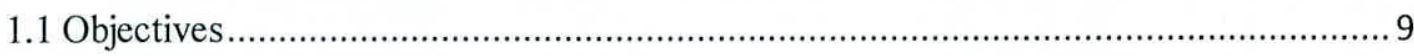

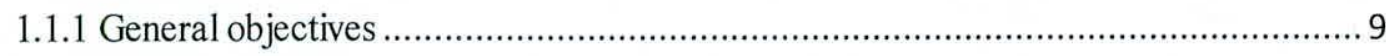

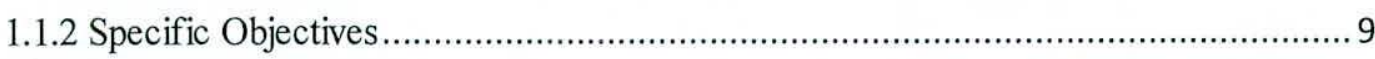

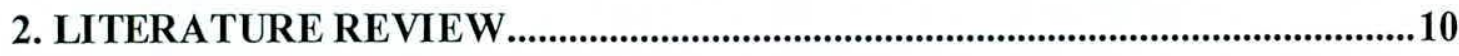

2.1 Anatomy and physiology of the female reproductive system..................................... 11

2.1.1 Anatomy of the female reproductive system.................................................... 11

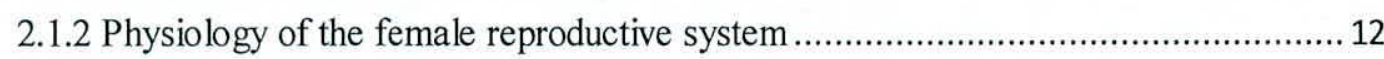

2.1.2.1 Oestrogen structure, receptors and functions ........................................ 12

2.1.2.1.1 Structure of oestrogen hormone …................................................... 12

2.1.2.1.2 Bio synthesis of oestrogens .......................................................... 13

2.1.2.1.3 Oestrogen receptors..................................................................... 14

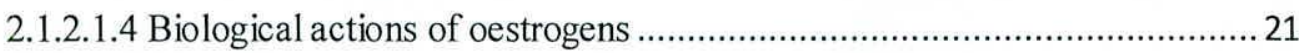

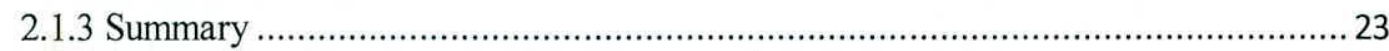

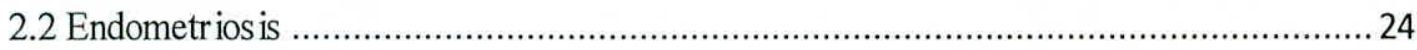

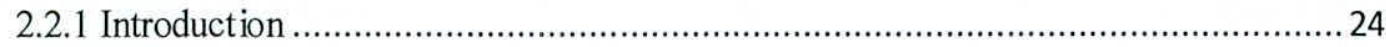

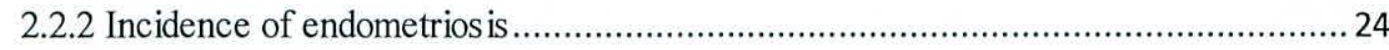

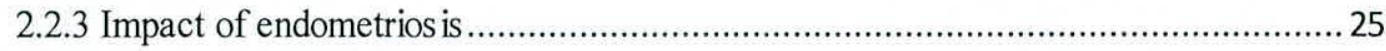




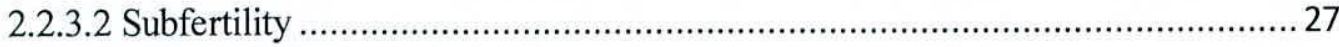

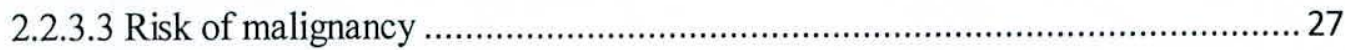

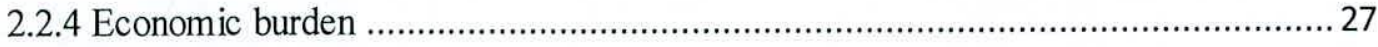

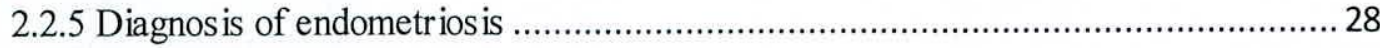

2.2.6 Treatment options for endometrios is ............................................................. 31

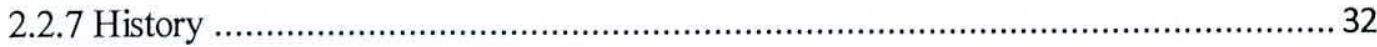

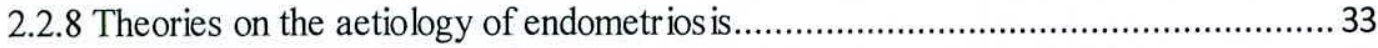

2.2.8.1 Sampson's theory of retrograde transplantation .......................................... 33

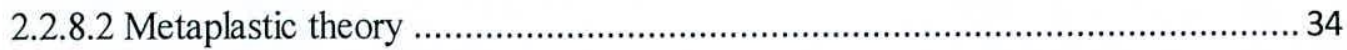

2.2.8.3 In situ development theory …………......................................................... 34

2.2.9 Current concepts on the aetiopathology of endometrios is .....................................34

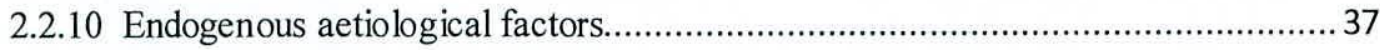

2.2.10.1 Eutopic endometrium in women with endometriosis................................... 37

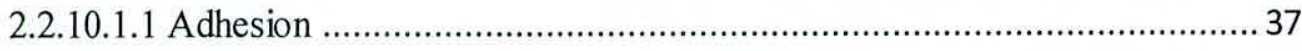

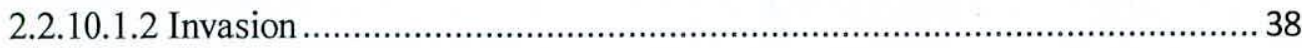

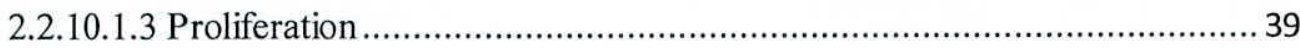

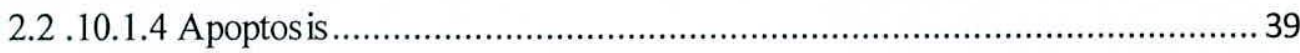

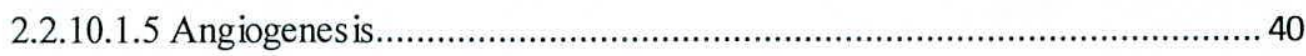

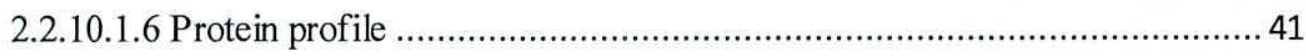

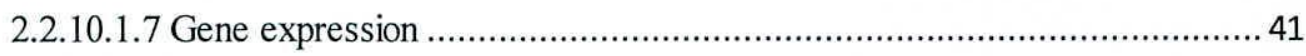

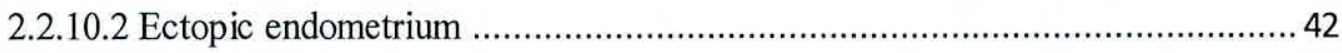

2.2.10.3 Inflammation and immune response ...................................................... 43

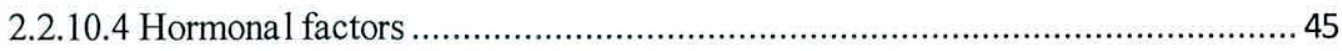

2.2.10.4.1 Biosynthes is of oestrogens in endometrios is ..................................... 45

2.2.10.4.2 Oestrogen receptors in endometriosis ................................................ 47 
2.2.10.4.3 Consequences of oestrogen activity in endometriosis 47

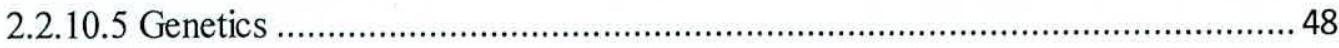

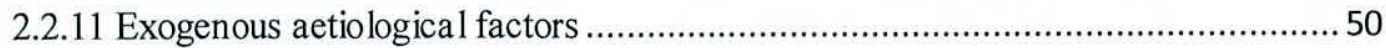

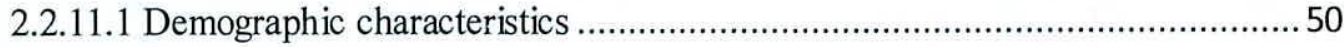

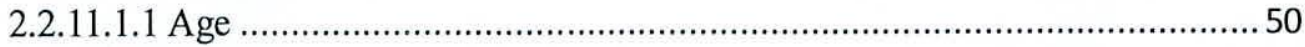

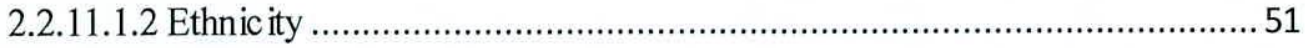

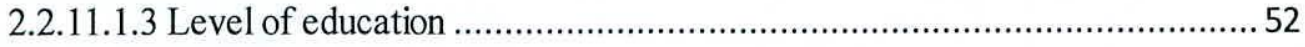

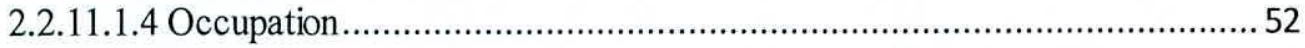

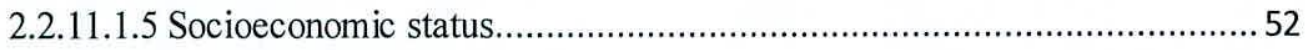

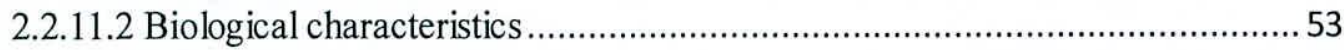

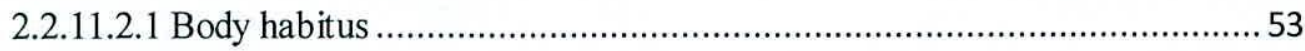

2.2.11.2.2 Menstrual and reproductive characteristics .......................................... 54

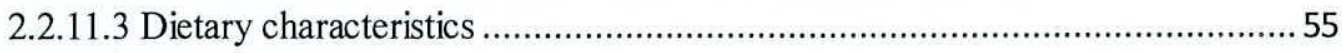

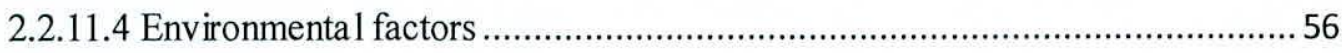

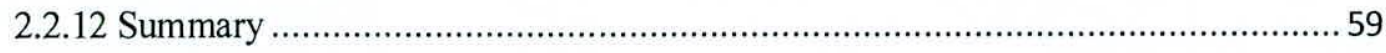

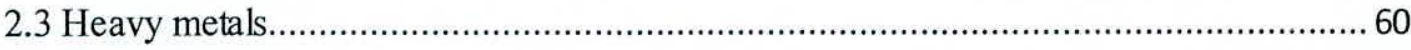

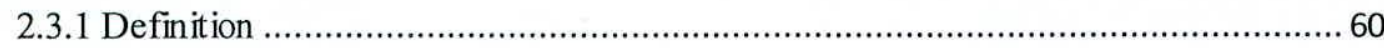

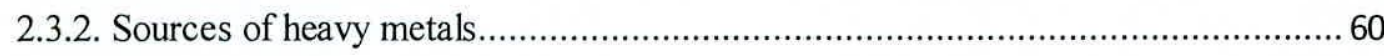

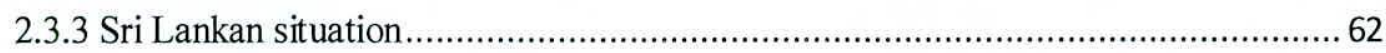

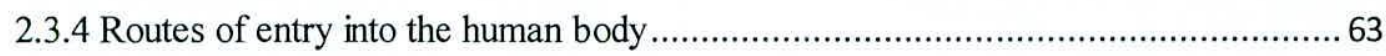

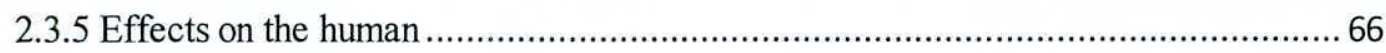

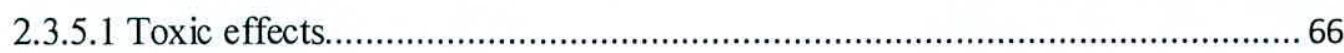

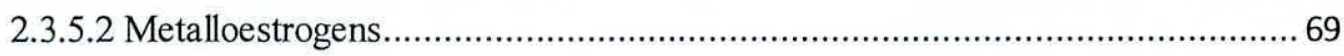

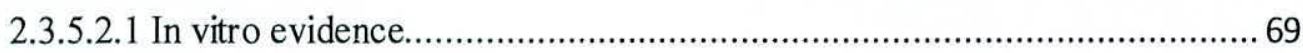

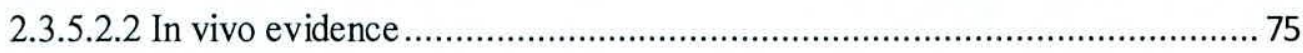

2.3.5.2.3 Metalloestrogens and endometrios is ................................................... 77 


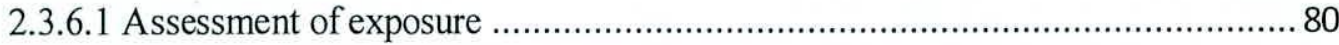

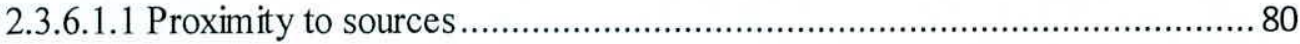

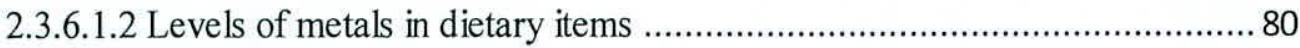

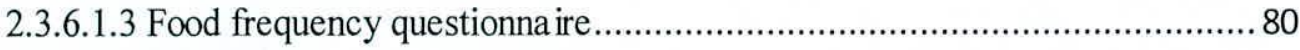

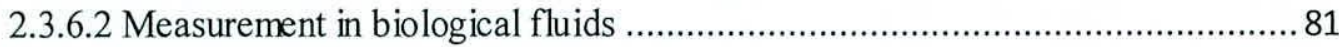

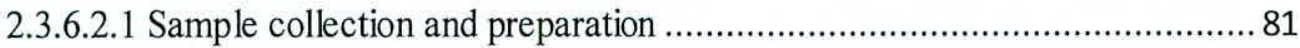

2.3.6.2.2 Methods for quant itative determination .............................................. 82

2.3.6.3 Evaluation of symptoms due to chronic heavy metal exposure .................... 83

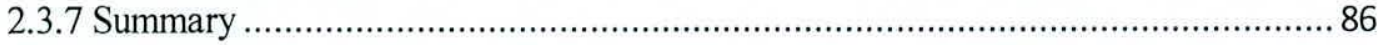

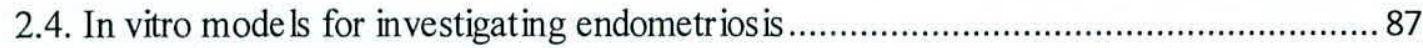

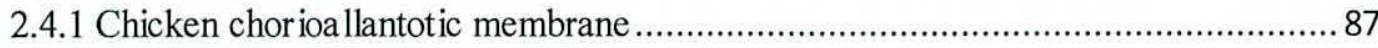

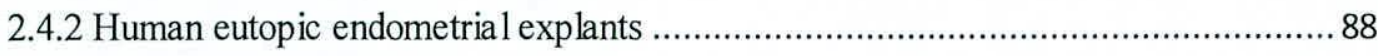

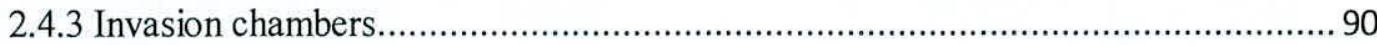

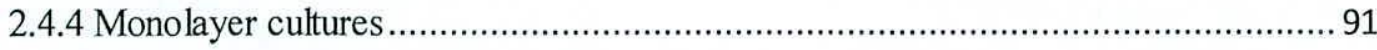

2.4.4.1 Early attempts to culture human endometrial cells ....................................... 91

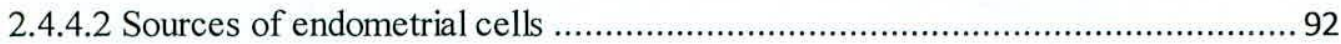

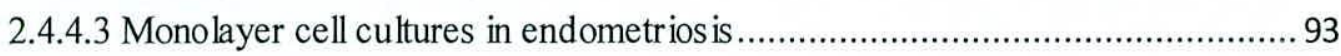

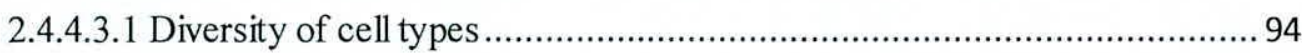

2.4.4.3.2 Applications of monolayer cell cultures in endometrios is ....................... 95

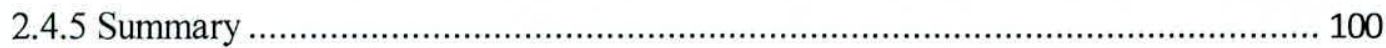

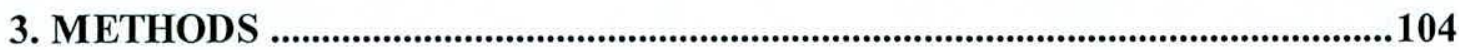

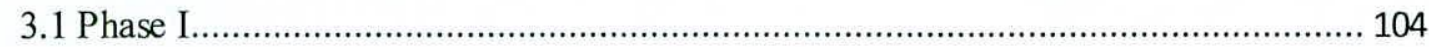

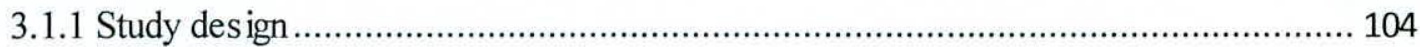

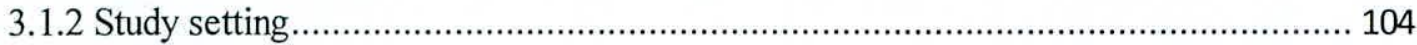

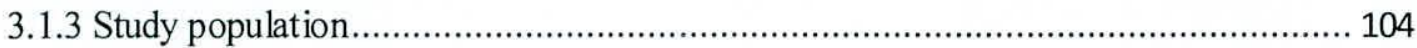




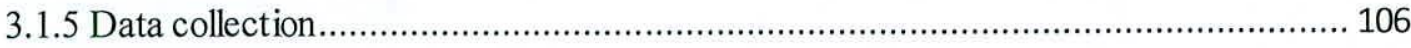

3.1.6 Collection of blood and tissue samples ......................................................... 108

3.1.7 Chemical digestion of blood and tissue samples ................................................ 110

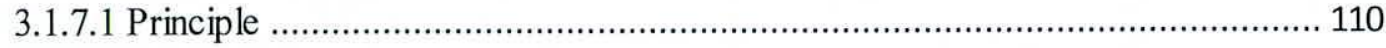

3.1.7.2 Procedure

3.1.7.3 Measures to minimize metal contamination during the chemical digestion ............ 111

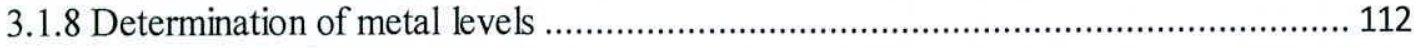

3.1.8.1 Determination of metal levels using Total-reflection X-ray Fluorescence .......... 112

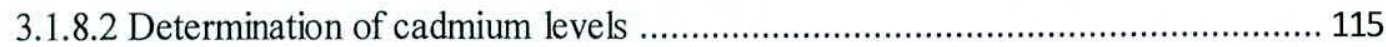

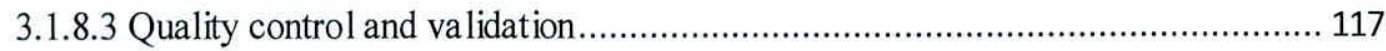

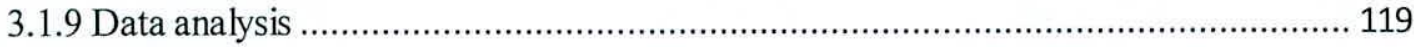

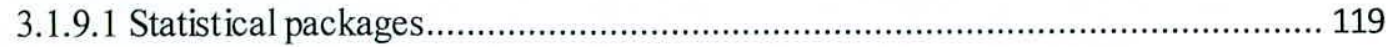

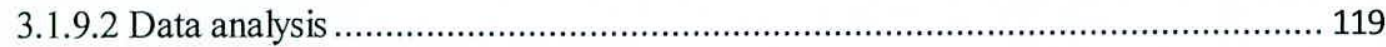

3.1.9.3 Analysis of blood and tissue metal levels...................................................... 120

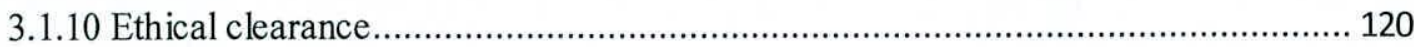

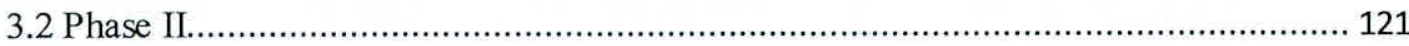

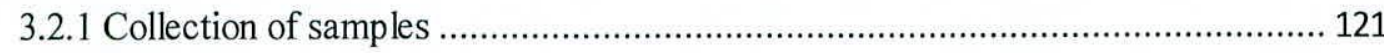

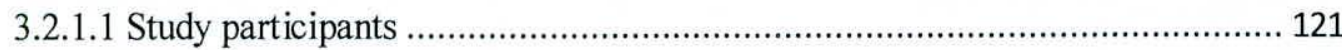

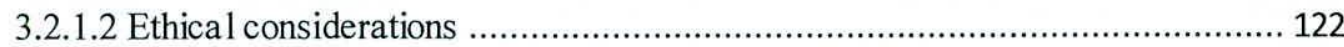

3.2.1.3 Collection of eutopic endometrial tissue samples ..................................... 122

3.2.2 Isolation of endometrial stromal cells.............................................................. 123

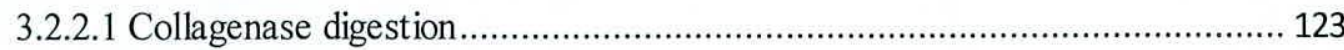

3.2.2.1.1 Preparation of collagenase solution....................................................... 123

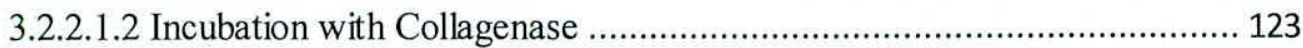

3.2.2.2 Isolation of stromal cells with filtration and centrifugation .......................... 124 
3.2.2.3 Determination of cell number

3.2.2.4 Determination of cell viability

3.2.3 Establishment of primary endometrial stromal cell (ESC) cultures.....

3.2.4 Establishment of sub cultures

3.2.5 Treatment of ESC cultures with metal compounds

3.2.5.1 Preparation of metal solutions

3.2.5.1.1 Metal compounds

3.2.5.1.2 Preparation of cadmium solutions

3.2.5.1.3 Preparation of nickel solution

3.2.5.1.4 Preparation of lead solution

3.2.5.2 Treatment of the cell monolayers with metal compounds 129

3.2.6 Determination of relative cell proliferation .................................................... 130

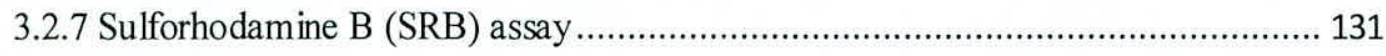

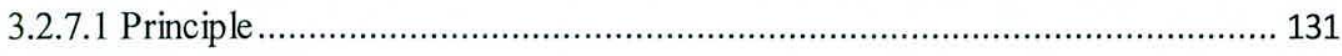

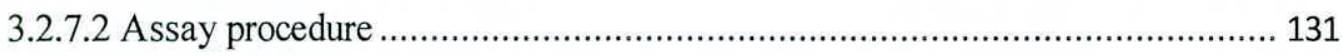

3.2.8 3-(4,5-dimethylthiazolyl-2)-2,5-diphenyltetrazolium bromide (MTT) assay......... 132

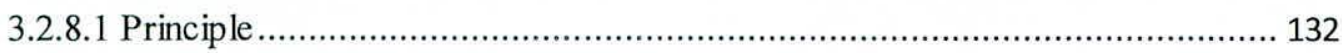

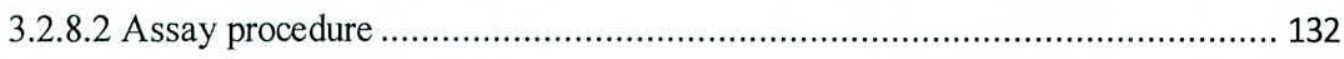

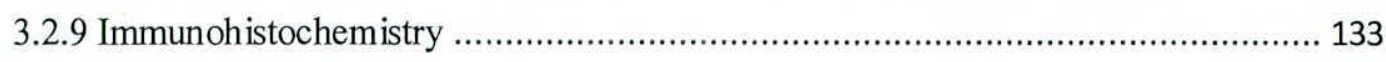

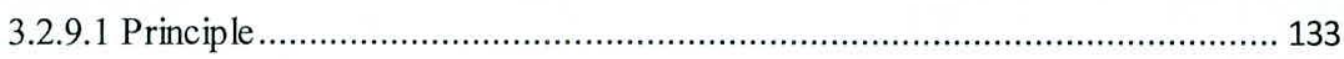

3.2.9.2 Preparation of cell monolayer for immunohistochemistry .......................... 134

3.2.9.3 Immunohistochemistry for vimentin and cytokeratin ................................ 134

3.2.9.4 Immunohistochemistry for ER and PR …........................................ 135

3.2.9. 5 Microscopic assessment of immunohistochemical staining ....................... 136

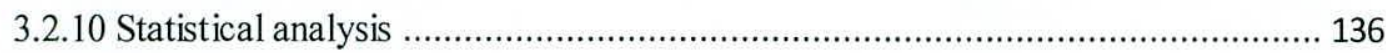

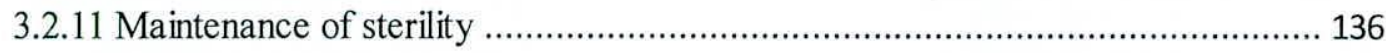


4.1. Results of the phase I.

4.1.1 Demographical characteristics

4.1.2 Biological characteristics 140

4.1.3 Multivariate analys is of demographic and biological characteristics. 142

4.1.4 Characteristics of women with endometrios is 142

4.1.5 Association of endometriosis with sources of heavy metal exposure 144

4.1.5.1 Proximity to sources of environmental pollution 144

4.1.5.2 Association of endometriosis with dietary items. 147

4.1.5.3 Association of endometriosis with drinking water and cooking utensils 147

4.1.6 Symptoms of chronic heavy metal exposure 150

4.1.7 Assessment of quality control and validation 152

4.1.8 Heavy metal concentrations in blood 154

4.1.9 Heavy metal levels in ectopic endometrial tissue 156

4.2 Results of Phase II 160

4.2.1 Characteristics of the participants 160

4.2.2 Characteristics of isolated endometrial stromal cells 161

4.2.3 Establishment of endometrial stromal cell cultures 161

4.2.3.1 Characteristics of primary endometrial cell cultures 161

4.2.3.2 Characteristics of individual endometrial stromal cells 162

4.2.4 Subcultures/ passages of endometrial stromal cells 162

4.2.5 Relative cell proliferation 166

4.2.6 SRB assay. 168

4.2.7 MTT assay 169

4.2.8 Immunohistochemical analysis of endometrial stromal cells .... 171

4.2.8.1 Immunohistochemistry for oestrogen receptor. 171 


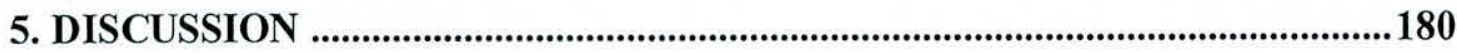

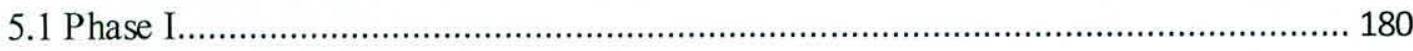

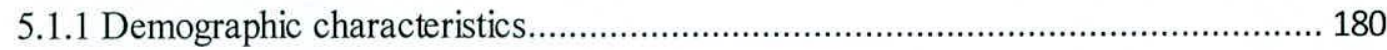

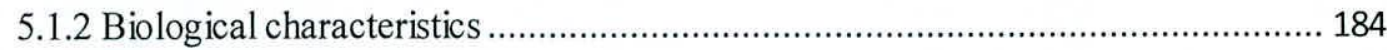

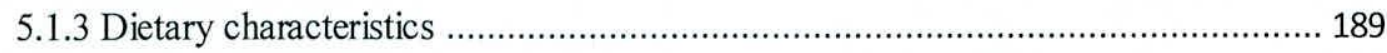

5.1.4 Association between heavy metal exposure and endometrios is ......................... 192

5.1.5 Whole blood heavy metal levels ................................................................ 193

5.1.6 Heavy metal levels in ectopic endometrial tissue ............................................ 196

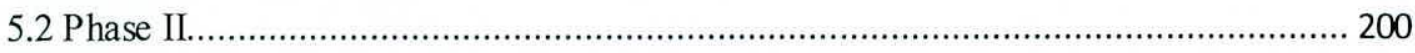

5.2.1 Establishment of primary endometrial stromal cell cultures ................................ 200

5.2.2 Effect of heavy metals on primary endometrial stromal cell cultures .................... 207

5.2.2.1 Relative cell proliferation of ESC .......................................................... 207

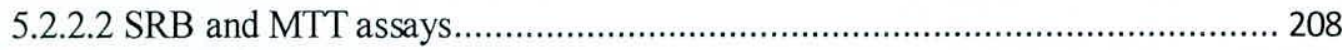

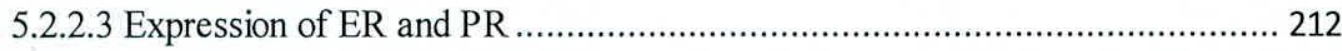

6. CONCLUSIONS AND RECOMMENDATIONS …...............................................216

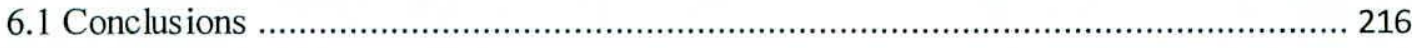

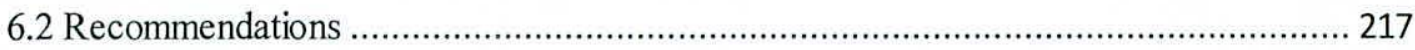

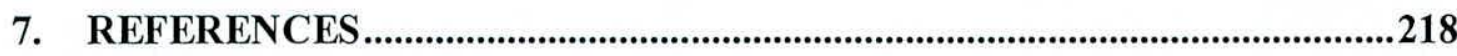

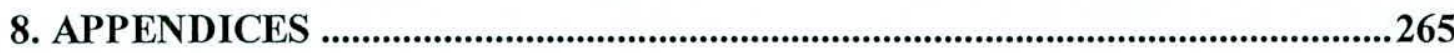

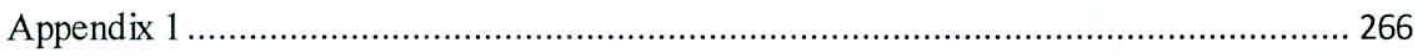

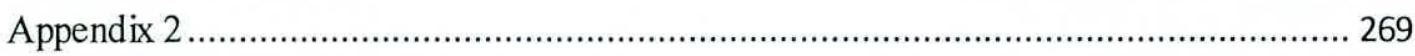

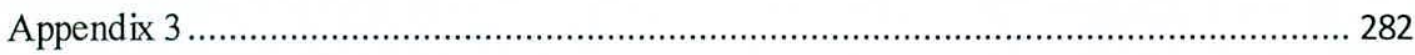

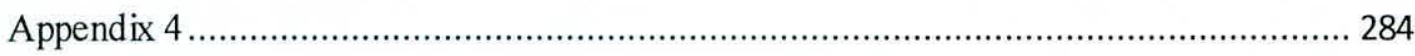

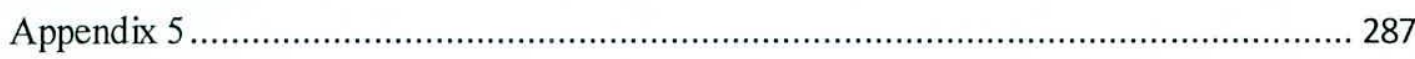




\section{LIST OF TABLES}

Page number

Table 2.1: Revised classification of endometriosis of the American

Society for Reproductive Medicine

Table 2.2: Characteristics of the main methods used in heavy metal analysis in biological samples

Table 2.3: Features of chronic exposure to heavy metals

Table 2.4: In vitro effects of currently used or novel compounds in endometriosis

Table 4.1: Demographic characteristics of women with or without endometriosis

Table 4.2: Menstrual and gynaecological characteristics of women with or without endometriosis

Table 4.3: Summary of conditional logistic regression analysis

Table 4.4: Stages of endometriosis among women with endometriosis

Table 4.5: Modes of treatment received by women with endometriosis

Table 4.6: Prevalence of symptoms associated with endometriosis in women with or without endometriosis

Table 4.7: Association between close proximity $(<100 \mathrm{~m})$ to sources of environmental pollution and endometriosis

Table 4.8: Association between food items and endometriosis

Table 4.9: Sources of drinking water, utensils used for storage of drinking water and cooking in households of women with and without endometriosis

Table 4.10: Prevalence of symptoms due to chronic heavy metal exposure in women with or without endometriosis

Table 4.11: Comparison between certified and obtained values for the reference standards

Table 4.12: Concentrations of heavy metals in whole blood $(\mu \mathrm{g} / \mathrm{L})$ of women with or without endometriosis 
Table 4.13: Risk of endometriosis according to the tertile values of cadmium, lead, iron and zinc

Table 4.14: Levels of heavy metals in ectopic endometrial tissue $(\mu \mathrm{g} / \mathrm{Kg})$ and in whole blood $(\mu \mathrm{g} / \mathrm{L})$ of women with endometriosis different sites in women with endometriosis

Table 4.16: Correlation between metal levels $(\mu \mathrm{g} / \mathrm{Kg})$ in ectopic endometrial tissue

Table 4.17: Stages of endometriosis in women with endometriosis

Table 4.18: Cell number and viability of isolated endometrial stromal cells in women with and without endometriosis

Table 5.1: Comparison of the demographic and biological characteristics of women with endometrio sis 


\section{LIST OF FIGURES}

Page number

Figure 1.1 Gaps in scientific knowledge addressed by the present study 8

Figure 2.1 Organizational structure of the literature review....................... 10

Figure 2.2 Female reproductive system .....................................................

Figure 2.3 Structures of naturally occurring oestrogens............................. 12

Figure 2.4 Synthesis of naturally occurring oestrogens............................. 13

Figure 2.5 Structure of the oestrogen receptor ………………………...... 14

Figure 2.6 Diversity of the ligands that activate the oestrogen 17

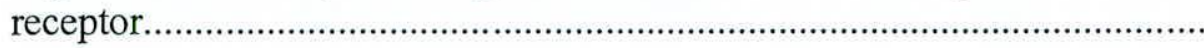

Figure 2.7 Mechanism of oestrogen receptor activation.............................. 18

Figure 2.8 Current concepts on the aetiopathology of endome triosis........ $\quad 36$

Figure 2.9 Complex interplay of endogenous aetiological factors in the 49 pathogenesis of endometriosis.

Figure 2.10 Sources of heavy metals and their routes of entry into humans

Figure 2.11 In vitro metalloestrogenic effects of cadmium ..................... $\quad 74$

Figure 3.1 Summary of the methodology for the data and sample 109 collection in phase I.

Figure 3.2 Sample preparation and metal analysis procedure................... 112

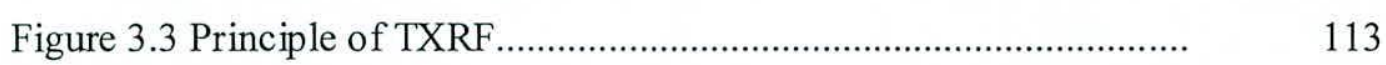

Figure 3.4 A typical spectrum obtained using the TXRF.......................... 115

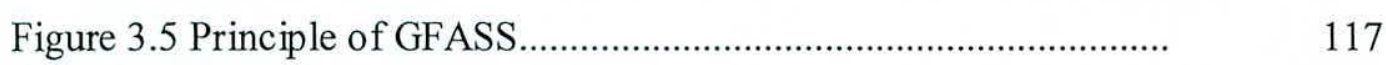

Figure 3.6 Serial dilution of cadmium solutions (A to E).......................... 128

Figure 3.7 Summary of the methodology in phase II................................. 137

Figure 4.1 Primary endometrial stromal cell cultures under the inverted 163 phase contrast microscope. 
Figure 4.2 Endometrial stromal cells in long term cultures under the

phase contrast microscope.

Figure 4.3 Endometrial stromal cells following immune histochemical staining using primary antibodies for (A) vimentin (B) cytokeratin and (C) universal negative control under the binocular microscope.

Figure 4.4 Endometrial stromal cells under the phase contrast microscope.

Figure 4.5 Endometrial stromal cell culture from a control at 90 days after the initial culture at the $17^{\text {th }}$ passage (subculture) following immunohistochemical staining using primary antibodies for $(A)$ vimetin (B) cytokeratin and (C) universal negative control; under the binocular microscope.

Figure 4.6 Endometrial stromal cell culture from a patient at 60 days after the initial culture at the $10^{\text {th }}$ passage (subculture) following immunohistochemical staining using primary antibodies for $(A)$ vimetin (B) cytokeratin and (C) universal negative control; under the binocular microscope

Figure 4.7 Relative proliferation of Endometrial Stromal Cells from women without endometriosis and women with endometriosis after 24 hours and 48 hours of treatment with (A) $10^{-6} \mathrm{M} \mathrm{Cd}$ (b) $10^{-9} \mathrm{M} \mathrm{Ni}$ and (C) $10^{-9} \mathrm{MPb}$

Figure 4.8 Relative proliferation of endometrial Stromal Cells from women without endometriosis and women with endometriosis after 24 hours and 48 hours of treatment with a combination of $10^{-6} \mathrm{M} \mathrm{Cd}, 10^{-9} \mathrm{M}$ $\mathrm{Ni}$ and $10^{-9} \mathrm{M} \mathrm{Pb}$

Figure 4.9 Results of SRB assay following 48 hours of incubation with different concentrations of $\mathrm{Cd}\left(10^{-8} \mathrm{M}\right.$ to $\left.10^{-3} \mathrm{M}\right)$ and a combination of metal compounds $\left(10^{-6} \mathrm{M} \mathrm{Cd}, 10^{-9} \mathrm{M} \mathrm{Ni}\right.$ and $\left.10^{-9} \mathrm{M} \mathrm{Pb}\right)$

Figure 4.10 Results MTT assay following 48 hours of incubation with different concentrations of $\mathrm{Cd}\left(10^{-8} \mathrm{M}\right.$ to $\left.10^{-3} \mathrm{M}\right)$ and combination of metal compounds $\left(10^{-6} \mathrm{M} \mathrm{Cd}, 10^{-9} \mathrm{M} \mathrm{Ni}\right.$ and $\left.10^{-9} \mathrm{M} \mathrm{Pb}\right)$

Figure 4.11 Immunohistochemical staining of endometrial stromal cells with primary antibody for oestrogen receptor, following treatment with $10^{-6} \mathrm{M} \mathrm{Cd}$ for 24 hours and 48 hours in (A) women with endometriosis (B) women without endometriosis 
Figure 4.12 Immunohistochemical staining of endometrial stromal cells with primary antibody for progesterone receptor, following treatment with $10^{-6} \mathrm{M} \mathrm{Cd}$ for 24 hours and 48 hours in (A) women with endometriosis (B) women without endometriosis.

Figure 4.13 Immunohistochemical staining of endometrial stromal cells with primary antibody for oestrogen receptor, following treatment with $10^{-9} \mathrm{M} \mathrm{Ni}$ for 24 hours and 48 hours in (A) women with endometriosis (B) women without endometriosis.

Figure 4.14 Immunohistochemical staining of endometrial stromal cells with primary antibody for progesterone receptor, following treatment with $10^{-9} \mathrm{M} \mathrm{Ni}$ for 24 hours and 48 hours in (A) women with endometriosis (B) women without endometriosis

Figure 4.15 Immunohistochemical staining of endometrial stromal cells with primary antibody for oestrogen receptor, following treatment with $10^{-9} \mathrm{M} \mathrm{Pb}$ for 24 hours and 48 hours in (A) women with endometriosis (B) women without endometriosis.

Figure 4.16 Immunohistochemical staining of endometrial stromal cells with primary antibody for progesterone receptor, following treatment with $10^{-9} \mathrm{M} \mathrm{Pb}$ for 24 hours and 48 hours in (A) women with endometriosis (B) women without endometriosis

Figure 4.17 Immunohistochemical staining of endometrial stromal cells with primary antibody for oestrogen receptor, following treatment with a combination of $10^{-6} \mathrm{M} \mathrm{Cd}, 10^{-9} \mathrm{M} \mathrm{Ni}$ and $10^{-9} \mathrm{M} \mathrm{Pb}$ for 24 hours and 48 hours in (A) women with endometriosis (B) women without endometriosis

Figure 4.18 Immunohistochemical staining of endometrial stromal cells with primary antibody for progesterone receptor, following treatment with a combination of $10^{-6} \mathrm{M} \mathrm{Cd}, 10^{-9} \mathrm{M} \mathrm{Ni}$ and $10^{-9} \mathrm{M} \mathrm{Pb}$ for 24 hours and 48 hours in (A) women with endometriosis (B) women without endometriosis

Figure 5.1 Interplay of demographic and biological characteristics in the present study 


\section{LIST OF ABBREVIATIONS}

\begin{tabular}{|c|c|c|}
\hline AKT & - & Threonine/serine kinases \\
\hline AP-1 & - & Activating Protein-1 \\
\hline As & - & Arsenic \\
\hline $\mathrm{Au}$ & - & Gold \\
\hline Bcl-2 & - & B-Cell lymphoma/leukaemia-2 \\
\hline BLyS & - & B lymphocyte stimulator \\
\hline $\mathrm{Ca}$ & - & Calcium \\
\hline CAM & - & Chicken chorioallantoic membrane \\
\hline Cd & - & Cadmium \\
\hline $\mathrm{CdCl}_{2}$ & - & Cadmium chloride \\
\hline CEA & - & Central Environmental Authority \\
\hline Co & - & Cobalt \\
\hline $\mathrm{Cr}$ & - & Chromium \\
\hline $\mathbf{C u}$ & - & Copper \\
\hline $\mathbf{E}_{1}$ & - & Oestrone \\
\hline $\mathbf{E}_{2}$ & - & $17 \beta$-oestradiol \\
\hline $\mathbf{E}_{3}$ & - & Oestriol \\
\hline ECM & - & Extracellular matrix \\
\hline EGFR & - & Epidermal growth factor receptor \\
\hline ER & - & Oestrogen receptor \\
\hline ERa & - & Oestrogen receptor alpha \\
\hline ERß & - & Oestrogen receptor beta \\
\hline ERE & - & Oestrogen response elements \\
\hline ERK & - & Extra cellular signal-regulated kinas \\
\hline
\end{tabular}




\begin{tabular}{|c|c|}
\hline $\mathrm{Fe}$ & - Iron \\
\hline FSH & - Follicular stimulating hormone \\
\hline GnRH & - Gonadotropin releasing hormone \\
\hline Hg & - Mercury \\
\hline HPO & - Hypothalamo-pituitary-ovarian axis \\
\hline IHC & - Immonohistochemistry \\
\hline IL & - Interleukin \\
\hline $\mathbf{K}$ & - Potassium \\
\hline mER & - Membrane oestrogen receptor \\
\hline MAPK & - Mitogen-activated protein kinase \\
\hline MMP & - Matrix metalloproteinase \\
\hline NK & - Natural killer \\
\hline $\mathrm{Ni}$ & - Nickel \\
\hline NF-к $\beta$ & - Nuclear Factor- $\kappa \beta$ \\
\hline NSAID & - Nonsteroidal antiinflammatory drug \\
\hline OD & - Optical density \\
\hline L1 CAM & - L1 cell adhesion molecule \\
\hline LH & - Luteinizing hormone \\
\hline $\mathbf{P}$ & - Phosphorus \\
\hline $\mathbf{P b}$ & - Lead \\
\hline PF & - Peritoneal fluid \\
\hline PMC & - Peritoneal mesothelial cell \\
\hline PR & - Progesterone receptor \\
\hline PTWI & - Provisional tolerable weekly intake \\
\hline $\mathbf{S}$ & - Sulphur \\
\hline
\end{tabular}


SERM - Selective oestrogen receptor modulator

Sn $\quad-$ Tin

TFF 1 - Trefoil factor 1

TIMP - Tissue inhibitors of matrix metalloproteinase

TNFa - Tumour necrosis factor $\alpha$

TSP-1 - Thrombospondin-1

TXRF - Total-reflection X-ray Fluorescence

WHO - World Health Organization

uPA - Urokinase plasminogen activator

UK - United Kingdom

US - United States

UV - Ultraviolet

VEGF - Vascular endothelial growth factor

Zn $\quad-$ Zinc 


\section{ACKNOWLEDGEMENTS}

- Work described in this thesis constitutes support by many individuals in at least five different institutions where financial assistance was provided by four separate funding sources.

- The original research question on the association of heavy metals and endometriosis was first posed by Prof. Hemantha Senanayake of University of Colombo. Thus I would like to acknowledge Prof. Hemantha Senanayke for supervising me during this research project that was based on his original idea.

- Dr. Roshini Peiris-John who was always well tuned to conduct quality research inspired me in many ways. She opted to supervise me even after her resignation from the University of Sri Jayewardenepura despite a busy schedule.

- Meeting Prof. Rajitha Wickramasinghe and being supervised by him were indeed life time experiences for me. I would like to thank him for his input not only as a statistician but also as an internationally recognized researcher.

- The opportunity to work under Prof. Kamani Tennekoon as a clinical research assistant back in 2005 was a turning point in my professional life. Prof. Tennekoon was a pillar of strength for me during this project. I will eternally cherish the memories of Prof. Tennekoon correcting my thesis in her usual methodical manner despite physical constraints.

- I am indebted to Prof. Sharaine Fernando for stepping in as the internal supervisor at a very difficult stage of this project. Her assistance helped me in numerous ways to concentrate on the completion of the bench work and writing of the thesis. I deeply appreciate the personal interest taken by Prof. Fernando that enabled me to complete my $\mathrm{PhD}$. 
- Senior collegues at the Department of Physiology Prof. Sivithri Wimalasekara, Prof. Priyadarshika Hettiarchchi, Dr. D.K. Ruberu, Dr. Chandana Hewage and Dr Himasu Waidyaseka helped me in many ways towards the successful completion of this study. I would like to thank them, especillly for allowing me to take study leave for one and a half years.

- I would like to thank the present Dean of Faculty of Medical Sciences Prof. Mohan De Silva for the assisstance.

- Prof. Jayantha Jayawardana former Dean of Faculty of Medical Sciences is acknowledged for the support given during the initial stages of this study.

- In addition to granting me study leave, the University of Sri Jayewardenepura was the first funding source whose research grant (ASP/6/Re/2008/06) that enabled the initiation of this study. Dr. Narada Warsasuriya, Former Vice Chancellor of University of Sri Jayewardenepura is acknowledged for approving the above grant.

- I would like to express my deep sense of gratitude to Dr. N.L.A. Karunaratne, Vice Chancellor of University of Sri Jayewardenepura who never hesitated whenever a request was made for his assistance.

- University Grants Commission (UGC) is acknowledged for providing the grant that was instrumental in upgrading my MPhil to a $\mathrm{PhD}$. I would like to thank the staff at the International Coorperation division of the UGC for all the support.

- I wish to express sincere thanks to the National Coordinating Committee on Reproductive Health Research of Sri Lanka (NCC-HRP/ WHO) for providing the necessary financial assisstance that enabled the establishment of endometrial stromal cell cultures. 
- International Training and research on environmental and occupational health (ITREOH) programme (NIH grant-Two5497-07) of the University of Alabama, Birmingham, USA is acknowledged for the financial assistance and training during this project.

- Staff at the Professorial Gynacology unit of the National Hospital and staff of Ward 16 of the De Soyza Maternity Hospital Colombo are acknowledged for the cooperation during data collection.

- I wish to thank the staff of the Operating Theatre A of the National Hospital Colombo for the excellent support during sample collection.

- Mr. Vajira Waduge and the staff at the Atomic Energy Authority are acknowledged for all the support during prepartion and analysis of samples.

- Dr. M.S.M Iqbal and Mrs. D Aluthpatabendi at the Institute of Fundamental Studies, Kandy are acknoeledged for the assistance in cadmium analysis.

- I wish to thank Staff and colleagues at the Institute of Biochemistry, Molecular Biology and Biotechnology of University of Colombo, especially Mr. Sameera Samarakoon, Scientific Assisstant (Cell culture) who made my stay at the IBMBB indeed a pleasurable one.

- My parents are fondly remembered for providing me love, care and a good education without which none of this would have been possible.

- Last but not the least; I would like to thank all the women who volunteered to participate in this study without whose support this thesis would not have been a reality. 


\title{
Association between endometriosis and heavy metals in a group of Sri Lankan women of reproductive age
}

\section{Wedikara Arachchige Nalinda Yasanga Silva}

\begin{abstract}
Heavy metals such as cadmium, nickel and lead activate the oestrogen receptor (ER) to exert oestrogenic effects; thus implicated in the aetiology of endometriosis an oestrogen dependant disease. A purpoted role of heavy metals in the continuation of ectopic endometrial tissue could be hypothesized.
\end{abstract}

The objectives of this study were to compare the demographic, biological, exposure status of heavy metals, blood levels of heavy metals as well as the effects of heavy metals on endometrial stromal cell cultures between women with endometriosis and women with no evidence of the disease. In addition, presence of heavy metal in ectopic endometrial tissue was investigated.

In this case-control study women with endometriosis $(n=150)$ were compared with agematched controls $(n=150)$ with no evidence of endometriosis, both confirmed by laparoscopy or laparotomy. A pre tested interviewer-administered questionnaire was used for data collection. In a sub population of women ( $\mathrm{n}=50$ in each group), venous blood samples and ectopic endometrial tissue samples were obtained and digested with supra pure $65 \% \mathrm{HNO}_{3}$. Blood and tissue samples were analyzed for heavy metals using Total-reflection X-ray Fluorescence and graphite furnace atomic absorption spectroscopy. From both groups ( $\mathrm{n}=10$ in each group) eutopic endometrial samples were obtained to isolate endometrial stromal cells (ESC). Primary ESC cultures were established in RPMI medium and the cultures in the third passage were treated with $\mathrm{Cd}$, $\mathrm{Pb}$ and $\mathrm{Ni}$ at concentrations of $10^{-6} \mathrm{M}, 10^{-9} \mathrm{M}$ and $10^{-9} \mathrm{M}$ respectively. At $24 \mathrm{~h}$ and $48 \mathrm{~h}$ 
the relative cell proliferation was calculated using the Neubauer haemocytometer, while Progesterone receptor (PR) and ER expression were assessed by immunohistochemistry. SRB and MTT assays were performed following 48 hours of exposure of ESC cultures of both groups to $\mathrm{Cd}$ at concentrations of $10^{-8} \mathrm{M}$ to $10^{-3} \mathrm{M}$.

Chi square tests and odds ratios (OR) (McNemar's) were used to determine associations between dichotomous variables. Conditional logistic regression analysis was done to adjust for potential confounding variables. Log transformed blood levels of metals were compared using paired t-test while blood and tissue metal levels were correlated using the spearman rank correlation. ANOVA was used to analyze relative cell proliferation, SRB and MTT results.

The risk of endometriosis was 2.084 times greater among those with an education above Advanced Level as compared to those having an education below Advanced Level ( $p=0.021)$ after adjusting for confounding factors. Endometriosis was commoner among women living close to a main road ( $\mathrm{OR}=1.694 ; 95 \% \mathrm{CI}=1.037-2.767)$ (unadjusted) as compared to the respective reference group. Women with endometriosis had significantly higher $(P=0.011)$ geometric mean $(95 \% \mathrm{CI})$ blood nickel levels $[2.65$ (1.94-3.38) $\mu \mathrm{g} / \mathrm{L}]$ as compared to women without endometriosis $[0.80(0.70-0.90)$ $\mu \mathrm{g} / \mathrm{L}$ ]. Blood levels [women with vs. without] of cadmium [0.84 (0.17-1.98) vs 0.85 $(0.26-1.45) \mu \mathrm{g} / \mathrm{L}]$ and lead $[11.09(0.67-13.36)$ vs $6.90(1.72-8.09) \mu \mathrm{g} / \mathrm{L}]$ were similar in the two groups ( $p=0.289$ and $p=0.123$ respectively). The geometric mean $(95 \% \mathrm{CI})$ levels of cadmium, nickel and lead detected in the ectopic endometrial tissue of women with endometriosis were 2.86 (2.13-3.60), 17.55 (13.15-21.94) and 25.78 (18.49-33.08) $\mu \mathrm{g} / \mathrm{Kg}$ respectively with no significant correlation between blood and tissue levels of 
cadmium, nickel or lead. Cd treatment increased the relative proliferation in ESC and at $48 \mathrm{~h}$, cell proliferation was higher in cultures form women with endometriosis $(p=0.02)$ than in women with no evidence of disease. Treatment with $\mathrm{Cd}$ reduced expression of ER and increased expression of PR in the ESC from women with endometriosis when compared to normal women. Relative cell proliferation and alterations in ER and PR levels were most prominent in ESC of women with endometriosis at $48 \mathrm{~h}$. In the MTT assay, while significant differences were noted at $10^{-6} \mathrm{M}$ of $\mathrm{Cd}$ there was no dose dependent response.

In this group of Sri Lankan women in the reproductive age, endometriosis is commoner among those who are more educated. Cadmium, nickel and lead were present in ectopic endometrial tissue and higher levels of nickel in blood were detected in women with endometriosis compared to women without endometriosis. Cadmium was capable of inducing oestrogenic effects in cultured endometrial stromal cells that were more prominent in women with endometriosis. 